\title{
Relative humidity vertical profiling using lidar-based synergistic methods in the framework of the Hygra-CD campaign
}

\author{
Lev D. Labzovskii ${ }^{1}$, Alexandros Papayannis ${ }^{2}$, Ioannis Binietoglou ${ }^{3,4}$, Robert F. Banks ${ }^{5,6}$, Jose M. Baldasano ${ }^{5,7}$, \\ Florica Toanca $^{3}$, Chris G. Tzanis ${ }^{8}$, and John Christodoulakis ${ }^{8}$ \\ ${ }^{1}$ School of Environmental Science and Engineering, South University of Science and Technology of China, \\ Shenzhen 518055, China \\ ${ }^{2}$ Laser Remote Sensing Laboratory, Physics Department, National Technical University of Athens, \\ Athens, Zografou, 15780, Greece \\ ${ }^{3}$ Laser Remote Sensing Laboratory, National Institute of R\&D for Optoelectronics, Magurele (Ilfov), 07712, Romania \\ ${ }^{4}$ Raymterics S.A., Spartis 32, Metamorfosi Attikis, 14452, Greece \\ ${ }^{5}$ Earth Sciences Department, Barcelona Supercomputing Center-Centro Nacional de Supercomutación (BSC-CNS), \\ Barcelona, 08034, Spain \\ ${ }^{6}$ Department of Geoscience and Remote Sensing, Faculty of Civil Engineering and Geosciences, Delft University of \\ Technology, Delft, $2628 \mathrm{CN}$, the Netherlands \\ ${ }^{7}$ Environmental Modelling Laboratory, Technical University of Catalonia (UPC), Barcelona, 08028, Spain \\ ${ }^{8}$ Section of Environmental Physics and Meteorology, Department of Physics, National and Kapodistrian University of \\ Athens, Athens, 15784, Greece
}

Correspondence: Lev D. Labzovskii (lev@ sustc.edu.cn)

Received: 25 October 2017 - Accepted: 14 December 2017 - Published: 14 February 2018

\begin{abstract}
Accurate continuous measurements of relative humidity $(\mathrm{RH})$ vertical profiles in the lower troposphere have become a significant scientific challenge. In recent years a synergy of various ground-based remote sensing instruments have been successfully used for RH vertical profiling, which has resulted in the improvement of spatial resolution and, in some cases, of the accuracy of the measurement. Some studies have also suggested the use of highresolution model simulations as input datasets into RH vertical profiling techniques. In this paper we apply two synergetic methods for RH profiling, including the synergy of lidar with a microwave radiometer and high-resolution atmospheric modeling. The two methods are employed for $\mathrm{RH}$ retrieval between 100 and $6000 \mathrm{~m}$ with increased spatial resolution, based on datasets from the HygrA-CD (Hygroscopic Aerosols to Cloud Droplets) campaign conducted in Athens, Greece from May to June 2014. RH profiles from synergetic methods are then compared with those retrieved using single instruments or as simulated by high-resolution models. Our proposed technique for RH profiling provides improved statistical agreement with reference to radiosoundings by $27 \%$
\end{abstract}

when the lidar-radiometer (in comparison with radiometer measurements) approach is used and by $15 \%$ when a lidar model is used (in comparison with WRF-model simulations). Mean uncertainty of $\mathrm{RH}$ due to temperature bias in $\mathrm{RH}$ profiling was $\sim 4.34 \%$ for the lidar-radiometer and $\sim 1.22 \%$ for the lidar-model methods. However, maximum uncertainty in RH retrievals due to temperature bias showed that lidar-model method is more reliable at heights greater than $2000 \mathrm{~m}$. Overall, our results have demonstrated the capability of both combined methods for daytime measurements in heights between 100 and $6000 \mathrm{~m}$ when lidar-radiometer or lidar-WRF combined datasets are available.

Keywords. Atmospheric composition and structure (instruments and techniques)

\section{Introduction}

Relative humidity (RH) is a crucial parameter for atmospheric research, as it represents the current state of water vapor and ambient air related to saturation. Changes in $\mathrm{RH}$ 
may influence atmospheric optical properties such as visibility, which is often reduced due to RH variations in the atmosphere (Tang et al., 1981). Moreover, increased RH in the atmosphere may influence the physical properties of aerosols, causing condensation onto their surface, which subsequently triggers their hygroscopic growth. Not only does this growth affect the direct scattering of radiation (Hanel and Zankl, 1979; Hegg et al., 1996; Zieger et al., 2013), but also the process of cloud condensation nuclei (CCN) formation (Charlson et al., 1992; Petters and Kreidenweis, 2007; Wex et al., 2008; Mochida, 2014). Previous studies have found that even minor changes in RH may affect processes such as cloud formation or precipitation (Kulmala et al., 1993; Tomkins, 2003; Sherwood et al., 2010; Altaratz et al., 2013). The interest in the role of $\mathrm{RH}$ in the modification of aerosol, precipitation and cloud microphysics, including $\mathrm{CCN}$ formation, has recently increased mainly due to the crucial role of aerosol-cloud interactions in climate change (Fan et al., 2007; Veselovskii et al., 2009; Zieger et al., 2013; GranadozMunoz et al., 2015; López and Ávila, 2016).

In addition, RH measurements are frequently used for evaluation studies aiming to predict the formation of clouds (Heerwaarden and Arellano, 2008) and aircraft contrails (Radel and Shine, 2007). No less important are the significant uncertainties in the estimation of global climate change parameters using climate modeling (Schneider et al., 2010). Usually these uncertainties are associated with $\mathrm{RH}$ variations, since water vapor acts as a global constraint in the climate system (Sherwood et al., 2010). Despite advancements in satellite remote sensing of water vapor, continuous quantification of RH in the low troposphere remains challenging. Vertical resolution of spaceborne measurements of water vapor and temperature constrains the accuracy of $\mathrm{RH}$ retrieval close to the ground (with spatial resolution of $\sim 1-2 \mathrm{~km}$ ) (Wulfmeyer et al., 2015). RH observations are based on water vapor and temperature measurements which are together frequently referred to as thermodynamic atmospheric profiling. A comprehensive description of the modern techniques for thermodynamic profiling by different instruments is given by Wulfmeyer et al. (2015), who have outlined the advantages, disadvantages and uncertainties of each instrument. Here, we present a brief description of different ground-based techniques for RH vertical profiling. One of the most frequently used instruments for RH vertical profiling are radiosondes. Radiosoundings provide vertical profiles of RH with spatial resolution of a few meters, and relatively high accuracy ( $\pm 4-5 \%$, depending on the time of the day) (Miloshevich et al., 2009). More automated RH vertical profiling is usually performed using passive and active remote sensing sensors which are able to measure both water vapor and temperature vertical distribution. The Atmospheric Emitted Radiance Interferometer (AERI) is an example of a passive sensor that can be used for water vapor and temperature quantification, based on atmospheric radiance measurements at the $15 \mu \mathrm{m} \mathrm{CO}$ band. Profiles of $\mathrm{RH}$ are pro- vided using a combination of AERI water vapor and temperature datasets from the ground up to $3000 \mathrm{~m}$, with a temporal resolution of $10 \mathrm{~min}$ (Feltz et al., 1998; Knuteson et al., 2004). The AERI system is, however, limited by coarse spatial resolution and often AERI cannot detect sharp and strong inversion layers (Mattis et al., 2002). Microwave radiometric measurements of temperature and humidity can provide water vapor and temperature vertical profiles as well. A microwave radiometer performs multifrequency measurements of brightness temperatures at high temporal resolution $(\sim 1 \mathrm{~s})$ and high accuracy from the surface $(0.6 \mathrm{~K})$ up to the middle troposphere (1.5 to $2 \mathrm{~K}$ ) (Hogg et al., 1983; Ware et al., 2003). Nevertheless, radiometer measurements suffer from coarse spatial resolution and substantial uncertainties in the retrieval of humidity and temperature at heights greater than $4000 \mathrm{~m}$, where only $5 \%$ of the independent information originates from radiometer measurements themselves (Rose et al., 2005). Active remote sensing instruments such as atmospheric lidar instruments have the ability to obtain high-resolution measurements of RH. To this end, two major techniques can be employed: the differential absorption lidar (DIAL) and the Raman lidar techniques. Each technique has its unique advantages and limitations. The DIAL water vapor profiling is based on the ratio of two elastic backscatter signals at two adjacent wavelengths and is affected by the temperature dependence of the water vapor molecular absorption, which is greater than 1-2\% (Wulfmeyer et al., 2015). Additionally, the presence of strong aerosol gradients may result in high systematic uncertainties that exceed the requirements of most desired applications (Theopold and Bosenberg, 1993). The Raman lidar technique for RH vertical profiling is based on the vibrational Raman scattering, which can be combined with the rotational Raman scattering to provide also the temperature vertical profiles (Arshinov et al., 1983). When a laser beam is emitted to the atmosphere at $355 \mathrm{~nm}$, the use of a Raman lidar at $387 \mathrm{~nm}$ (Raman shifting by atmospheric $\mathrm{N}_{2}$ ) and at $407 \mathrm{~nm}$ (Raman shifting by water vapor) enables the humidity-dependent parameter to be derived, which is subsequently normalized to the mixing ratio of water vapor. The most important constraints for current lidar instruments make most of them not applicable for water vapor measurements during daytime (due to high atmospheric background levels) and in the lowest several hundred meters of the troposphere (due to geometrical optics limitations).

Despite the relatively high performance of remote sensing instruments with regard to RH vertical profiling, we still suffer from a lack of a consistent robust method for continuous RH vertical profiling. One step forward in RH vertical profiling without the technological improvement of sensors is to use synergistic approaches, as proposed by Turner et al. (2000). This study presented the synergistic retrieval of RH based on a Raman lidar-retrieved water vapor mixing ratio and temperature profiles from the AERI instrument. Such synergy allowed the profiling of RH with high temporal res- 
olution to be performed. Another example of a synergetic approach towards RH vertical profiling has been presented by Nagel et al. (2001), where the authors approached RH profiling by combining lidar-derived humidity and temperature measurements from radiosoundings (launched every $10 \mathrm{~min}$ ). Moreover, Wang et al. (2011) demonstrated that density and the water vapor mixing ratio can be combined with temperature observations from a collocated rotational Raman lidar to provide RH vertical profiles. They showed relatively good agreement between lidar-retrieved and radiosonde observations, with a bias of up to $10 \%$ in the lowest $2000 \mathrm{~m}$ of the troposphere. A step forward in synergistic approaches towards accurate RH vertical profiling has been performed by Navas-Guzman et al. (2014). They demonstrated the method for RH vertical profiling based on the combination of Raman lidar humidity and temperature measurements from a collocated microwave radiometer, together with air density profiles taken from a standard atmospheric model scaled to nearground density measurements (COESA, 1976). This combined retrieval method resulted in an increased accuracy for continuous lidar-derived RH measurements in comparison with other remote sensing techniques. The resultant mean absolute deviation in RH compared to radiosonde data based on lidar-radiometer retrievals varied from 6 to $7 \%$ from 1000 to $5000 \mathrm{~m}$, respectively. Recently, Barrera-Verdejo et al. (2016) once again tested lidar-radiometer combination perspectives for water vapor studies. They developed a new approach for lidar-radiometer synergy for absolute humidity (AH) vertical profiling using an optimal estimation method. They combined multifrequency brightness temperature observations from a microwave radiometer and mixing ratio observations from a Raman lidar to retrieve high-resolution profiles of $\mathrm{AH}$. Their results proved that the combination of lidar and radiometer data can reduce the theoretical error by a factor of 2 in the lower troposphere when water vapor information is retrieved. All of these aforementioned methods and approaches have shown the perspectives of synergistic approaches for RH vertical profiling using collocated remote sensing instruments. More recently, Schutgens et al. (2017) presented promising results from the combination of spatially collocated observations and model simulations, pointing out that high-resolution model simulations can serve as a robust data source.

Based on the recommendations of Wulfmeyer et al. (2015) and Schutgens et al. (2017), in our study we used two synergistic approaches for RH vertical profiling. The first approach is based on the synergy of lidar and radiometer instruments, while the second method is based on lidar and numerical simulations from the Weather Research and Forecasting (WRF) model output. Our approaches use a combination of datasets, including water vapor mixing ratio from a Raman lidar, temperature profiles from radiometer, high-resolution simulations from the WRF model and air density profiles from the US Standard Atmosphere (1976) (COESA, 1976). Datasets were acquired during the HygrA-CD (Hygroscopic
Aerosols to Cloud Droplets) campaign conducted in Athens, Greece, from May to June 2014 (Papayannis et al., 2017). The main scope of this paper is to show the effectiveness of the two synergistic approaches in comparison with singleinstrument observations of RH from microwave radiometer and RH single simulations from WRF. As a second objective, we determine the effectiveness of these approaches according to crucial requirements applied for thermodynamic profiling techniques formulated and generalized by Wulfmeyer et al. (2015). These requirements can be applied for RH vertical profiling and include several points, among which the accuracy, spatial resolution and the minimum-maximum range of measurements.

\section{Instruments and models}

\subsection{Experimental site}

The datasets used in this work were collected during the HygrA-CD experimental campaign organized in the greater Athens area in the period 15 May-22 June 2014. The aim of the campaign was to bring together various instruments for atmospheric measurements in order to improve our current understanding of the impact of aerosols on clouds near the top of the planetary boundary layer (PBL). During the campaign period a variety of remote sensing and in situ instruments provided an important record of data on aerosols, clouds and local meteorology conditions. Among the five measurement sites involved in the HygrA-CD campaign, most of the data were obtained at the National Technical University of Athens (NTUA) $\left(37.97^{\circ} \mathrm{N}, 23.79^{\circ} \mathrm{E}, 212 \mathrm{~m}\right.$ a.s.1.) and the National Center of Scientific Research Demokritos (DEM) $\left(37.99^{\circ} \mathrm{N}, 23.82^{\circ} \mathrm{E}, 275 \mathrm{~m}\right.$ a.s.l.) (Papayannis et al., 2017).

\subsection{Multiwavelength lidar}

The aerosol and ozone lidar system (EOLE) multiwavelength Raman lidar system located at the campus of NTUA emitted pulses at three wavelengths: 355,532 and $1064 \mathrm{~nm}$, with energies per pulse of 240,260 and $300 \mathrm{~mJ}$, respectively, with a $10 \mathrm{~Hz}$ repetition rate. A receiving Cassegrainian telescope (primary mirror of $300 \mathrm{~mm}$ diameter and $600 \mathrm{~mm}$ focal length) was used to simultaneously receive the elastic backscattered lidar signals and the Raman ones (387, 407, $607 \mathrm{~nm}$ ). The full overlap of the system is achieved at $300 \mathrm{~m}$ from the lidar system (Kokkalis et al., 2012). Since the Raman signals are relatively weak, the Raman lidar measurements were performed only at nighttime under clear-sky conditions. The Raman-derived vertical profiles of the water vapor mixing ratio were calculated for 26 days of the campaign with different temporal scales ( $2 \mathrm{~min}, 1 \mathrm{~h}$ and $2 \mathrm{~h}$ ), which were selected depending on the various instruments' intercomparison: $2 \mathrm{~min}$ averaged data were used for comparisons with integrated radiometric values, and $2 \mathrm{~h}$ averaged data 
for the intercomparison with the radiosonde data, depending on the signal-to-noise ratio (SNR) of the lidar signals, as outlined as the minimum required resolution for effective thermodynamic profiling in the review from Wulfmeyer et al. (2015). The signal detection at the vibration Raman channels of 387 and $407 \mathrm{~nm}$ gives the possibility to retrieve the water vapor mixing ratio profiles defined as the ratio $\mu$ of the mass of water vapor to the mass of dry air $\left(\mathrm{g} \mathrm{kg}^{-1}\right)$ (Goldsmith et al., 1998) as extensively used in the last 2 decades for both daytime and nighttime measurements (Whiteman et al., 2006, 2010; Adam et al., 2007; Leblanc et al., 2011).

$\mu=C \frac{P_{\mathrm{WV}}(R)}{P_{\mathrm{N}_{2}}(R)} \frac{\exp \left[-\int_{0}^{R} \alpha_{\mathrm{N}_{2}}(\mathrm{~d} r) \mathrm{d} r\right]}{\exp \left[-\int_{0}^{R} \alpha_{\mathrm{WV}}(\mathrm{d} r) \mathrm{d} r\right]}$,

where $P_{\mathrm{WV}}$ is the detected lidar signal at the water vapor channel, $P_{\mathrm{N}_{2}}$ is the detected Raman signal at the nitrogen channel and $C$ is the calibration constant (see Sect. 3.1). The exponential part of Eq. (1) takes into account the ratio of the atmospheric transmission at $387\left(\alpha_{\mathrm{N}_{2}}\right)$ and $407 \mathrm{~nm}$ ( $\alpha_{\text {WV }}$ ) (Weitkamp, 2005). This difference in transmission is mainly contributed by Rayleigh scattering and can be calculated using temperature and pressure profiles taken from the US Standard Atmosphere 1976 (COESA, 1976) and rangeindependent Rayleigh scattering cross sections at appropriate wavelengths (Bucholtz, 1995). The standard profiles of pressure are assumed to be accurate for our purposes since the uncertainties introduced by their use are lower than $5 \%$. The difference between profiles of pressure obtained from radiosoundings and standard pressure profiles did not exceed $0.055 \mathrm{~kg} \mathrm{~m}^{-3}(4.5 \%)$. A more detailed description of the calibration procedure and the analysis of water vapor observations for the EOLE system can be found in Landulfo et al. (2009) and Mamouri et al. (2008), respectively, as well in Sect. 3.1 below.

\subsection{Microwave radiometer}

The HATPRO-G2 microwave radiometer consists of several components: two receiver units (22.24-31.4 and 51.3$59 \mathrm{GHz}$ ) with the relevant receiving optics, the ambient load, the internal scanning mechanism, the electronics and the data acquisition system (Rose et al., 2005). The microwave radiometer used in this study is manufactured by Radiometer Physics $\mathrm{GmbH}$ and belongs to the National Institute of R\&D in Optoelectronics (Bucharest, Romania). The HATPROG2, installed at NTUA, was calibrated before the observation campaign according to the procedure of radiometer absolute calibration using liquid nitrogen (Liljegren, 2002). The atmospheric radiation is measured at seven channels located in the $\mathrm{K}$ band, along the wing of the water vapor absorption line $(22.35 \mathrm{GHz})$, and seven channels located in the $\mathrm{V}$ band (Westwater, 1965), along the oxygen absorption complex (center is around $60 \mathrm{GHz}$ ) (Westwater et al., 2005). The vertical profiles of water vapor and temperature are inverted from observed brightness temperatures by using statistical regression algorithms, based on long-term datasets of collocated radiosoundings. The radiometer measurements used in this work have a temporal resolution of $15 \mathrm{~s}$ and a height-dependent vertical resolution: $200 \mathrm{~m}$ from 0 to $2000 \mathrm{~m}, 400 \mathrm{~m}$ from 2000 to $5000 \mathrm{~m}$ and $>500 \mathrm{~m}$ for heights above $5000 \mathrm{~m}$ (Löhnert et al., 2004; Rose et al., 2005; Mashwitz et al., 2013). The radiometric measurements (the data provided are integrated water vapor, IWV and vertical profiles of $\mathrm{AH}, \mathrm{RH}$ and temperature) were continuously performed from 15 May to 20 June 2014, except on 12 June where they were only available from 00:00 to 05:55 UTC and from 20:38 to 23:59 UTC, due to a technical shutdown. Radiometer-related random errors are analyzed based on previous studies which had determined that the error related to the systematic bias for $\mathrm{AH}$ retrievals using the regression method below $4000 \mathrm{~m}$ equals $0.8 \mathrm{~g} \mathrm{~m}^{-3}$. The random error of $0.5 \mathrm{~K}$ is taken into account in the PBL (up to $1000 \mathrm{~m}$ ) and $1.7 \mathrm{~K}$ between 1000 and $6000 \mathrm{~m}$ (Güldner, 2013; Crewell et al., 2001; Liljegren et al., 2005; Löhnert and Maier, 2012).

\subsection{Sun photometer}

The sun photometer is a passive remote sensing instrument that retrieves columnar atmospheric aerosol properties during daytime while pointing at the sun. For this work, we used aerosol columnar optical properties retrieved from a CIMEL CE-318-NEDPS9 sun photometer (Holben et al., 1998), which is a member site of the NASA AERONET (Aerosol Robotic Network) and was located on a nearby site around $5 \mathrm{~km}$ from NTUA (Papayannis et al., 2017). The sun photometer performs direct sun and sky measurements of solar radiances at eight wavelengths $(340,380,440,500,675$, 870,1020 and $1640 \mathrm{~nm}$ ). Aerosol optical depth is retrieved from direct sun measurements, while diffuse sun measurements are used by the inversion algorithms for columnar microphysical properties (Dubovik and King, 2000; Dubovik et al., 2006). Finally, measurements at $940 \mathrm{~nm}$ are used to estimate the integrated amount of precipitable water which is used in our work for the purposes of microwave radiometer validation and calibration.

\subsection{Radiosoundings}

During the campaign 17 high-resolution radiosondes (Vaisala RS92-SGP) were launched by the Hellenic National Meteorological Service (HNMS) at the Hellinikon airport $\left(37.88^{\circ} \mathrm{N}, 23.73^{\circ} \mathrm{E}\right)$. Vertical profiles of temperature were measured with an uncertainty of $0.3-0.4{ }^{\circ} \mathrm{C}$, relative humidity with an uncertainty around $4 \%$ and height uncertainty around $20 \mathrm{~m}$ (Nash et al., 2011). Here we use only the radiosoundings launched at 00:00 UTC, since only nighttime 
lidar measurements were considered for water vapor profiling. When high vertical resolution radiosonde data were not available, we used the radiosounding data (pressure, temperature, humidity) with sparser vertical resolution of about 50-700 $\mathrm{m}$ (low-resolution radiosoundings) obtained from the University of Wyoming website (http://weather.uwyo.edu/ upperair/uamap.shtml).

\subsection{WRF model configuration}

The WRF model (Skamarock et al., 2005) is a numerical weather prediction system designed for both atmospheric research and operational forecasting needs. Here, we use WRF model version 3.4.1 with the Advanced Research WRF (ARW) dynamical core. Three one-way nested domains are configured, with the finest domain on a $1 \mathrm{~km} \times 1 \mathrm{~km}$ grid over the greater Athens area. This high resolution is deemed sufficient to make simulations comparable with observational measurements in the complex area of Athens. Moisture parameters were simulated with 39 vertical levels at 50$100 \mathrm{~m}$ vertical spacing and with a $1 \mathrm{~h}$ writing period of the results. Daily simulations were run with a $36 \mathrm{~h}$ forecast cycle, including an allowance of $12 \mathrm{~h}$ for model spin-up. More details about the configuration of the WRF model during the HygrA-CD campaign are described in Banks et al. (2016).

\section{Evaluation of individual retrievals}

RH calculation requires profiling of water vapor, temperature and pressure. In this paper we used Raman lidar, a microwave radiometer and the WRF model to calculate the RH profiles. The calibration and evaluation of water vapor and temperature measurements are further presented.

\subsection{EOLE calibration for water vapor measurements - validation of lidar calibration results}

The lidar calibration is required since the measured quantity cannot be directly referred to as the water vapor mixing ratio. There are several methods to calibrate a Raman lidar system for water vapor profiling: by comparing with radiosonde observations, with collocated instrument observations (Whiteman et al., 1992; Foth et al., 2015) or by using hybrid normalization by calibrating lamps (Leblanc and McDermid, 2008). Here we apply the most commonly used method of the calibration using collocated radiosondes data within specific altitude ranges depending on the lidar signalto-noise ratio for two main reasons. Firstly, calibration using passive remote sensors may result in incomplete sampling of the water vapor column observed by lidar. Secondly, the use of calibrated lamps can be challenging and may lead to the increased amount of unexpected errors that are difficult to observe and compensate for (Whiteman et al., 2011). To derive the water vapor mixing ratio $(\mu)$, a calibration constant (C) has to be estimated (see Eq. 2) taking, as well, the ratio of the vibrational Raman lidar signals at $407\left(P_{\mathrm{WV}}\right)$ and $387 \mathrm{~nm}$ $\left(P_{\mathrm{N}_{2}}\right)$ :

$\mu=C \frac{P_{\mathrm{WV}}(R)}{P_{\mathrm{N}_{2}}(R)}$.

The mean value of $C$ is calculated from the bottom to the top layers of six high-resolution radiosoundings, taking into account the altitudes where its standard deviation is less than $10 \%$ (Table 1 ). In our case $C$ was estimated to be equal to 23.65 , with a weighted standard deviation of $9.5 \%$ (see Fig. 1, left panel). The values of the calibration constant with appropriate deviations for certain altitudes where averaging was performed (calculated from a series of radiosonde data), are presented in Table 1.

Furthermore, we compared the Raman lidar data with collocated low-resolution radiosoundings to check the sanity of the estimated $C$ value (the one shown in Table 1). The lowresolution calibration constant is 24.36 with a weighted standard deviation of $8.8 \%$ (Fig. 1., right panel) and the difference between the mean calibration constants is negligible. Relatively low differences with referenced radiosounding directly approves the validity of our calibration to meet the requirements (uncertainty should not exceed 10\%) from Leblanc and McDermid (2008). Therefore in this study we used calibration constant from high resolution radiosounding $(C=23.65 \pm 2.28)$.

As outlined by Leblanc et al. (2011), the calibration stability of a water vapor Raman lidar has to be insured by collocated water-vapor measurements. Therefore, an intercomparison of the IWV between the Raman lidar, sun photometer and microwave radiometer was performed. First, we compared the IWV from collocated radiometer and sun photometer measurements. Secondly, the lidar-derived IWV values ( 2 min resolution) were compared with the IWV values retrieved from the radiometer data at the same time with a temporal difference of less than $30 \mathrm{~s}$. The intercomparison was done in two steps because the Raman lidar provided the water vapor mixing ratio only during nighttime, while the sun photometer measured only during daytime. In the first step, the sun photometer and radiometer datasets were intercompared, while in the second step the radiometer and lidar datasets were intercompared. The sun photometer uncertainty in IWV calculation was considered to be $1.2 \mathrm{~kg} \mathrm{~m}^{-2}$ (Wang, 2008), while that of the microwave radiometer to be $0.8 \mathrm{~kg} \mathrm{~m}^{-2}$ (Rose et al., 2005). In our analysis we used in total 36 measurement pairs. The determination coefficient $\left(R^{2}\right)$ was estimated to be equal to 0.89 and only in one case was noted as inconsistent (Fig. 2, left panel). The average bias (b) of the radiometer data regarding the sun photometer was estimated to be equal to 1.02 . The intercomparison between lidar and the microwave radiometer was performed with some additional assumptions as in our study EOLE was not able to provide reliable data below $750 \mathrm{~m}$, due to geometric optical limitations of the system (see Sect. 3.2). An upper limit of the integration range of $9000 \mathrm{~m}$ has been chosen, such as to 
Table 1. Calibration constant mean values for each case of high-resolution radiosounding.

\begin{tabular}{lllrrrr}
\hline Date & $\begin{array}{l}\text { Lidar time } \\
(\mathrm{UTC})\end{array}$ & $\begin{array}{l}\text { Radiosonde } \\
\text { launch }^{\mathrm{a}}\end{array}$ & $\begin{array}{r}\text { Bottom } \\
(\mathrm{km})\end{array}$ & $\begin{array}{r}\text { Top } \\
(\mathrm{km})\end{array}$ & $\begin{array}{r}\text { Constant mean } \\
( \pm \sigma)\end{array}$ & $\begin{array}{r}\sigma \\
(\%)\end{array}$ \\
\hline 15 May 2014 & $21: 00-22: 00$ & $00: 00$ & 1.00 & 2.04 & $22.52 \pm 2.23$ & 9.94 \\
17 May 2014 & $19: 00-20: 00$ & $00: 00$ & 1.00 & 4.00 & $24.51 \pm 2.47$ & 10.00 \\
18 May 2014 & $22: 00-23: 00$ & $00: 00$ & 1.00 & 2.57 & $23.41 \pm 2.27$ & 9.78 \\
20 May 2014 & $22: 00-23: 00$ & $00: 00$ & 2.40 & 4.24 & $24.00 \pm 2.29$ & 9.70 \\
21 May 2014 & $21: 00-22: 00$ & $00: 00$ & 2.26 & 3.34 & $21.58 \pm 2.03$ & 9.50 \\
1 Jun 2014 & $23: 00-00: 00$ & $00: 00$ & 1.00 & 4.04 & $25.89 \pm 2.27$ & 8.84 \\
\hline
\end{tabular}

a All radiosondes are launched on the following day after the Raman lidar measurements.

Calibration constant variations (LR)

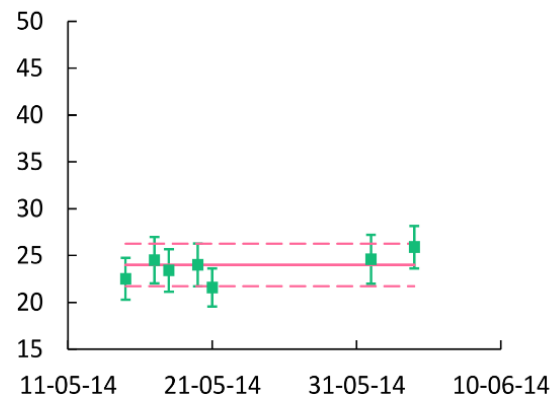

Calibration constant variations (HR)

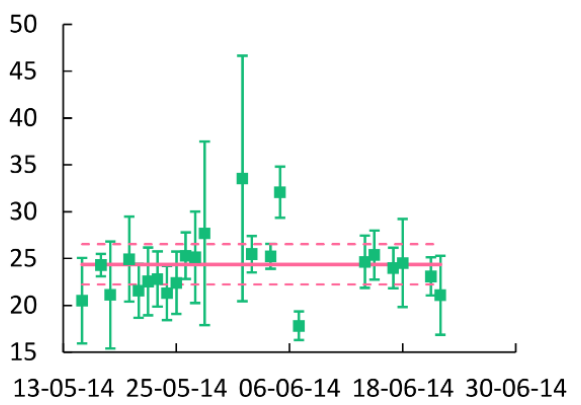

Figure 1. Variations of the water vapor calibration constant calculated based on low-resolution (LR) and high-resolution (HR) radiosoundings. Green bars: calibration constant variations, red solid line: mean calibration constant, dashed lines: maximum and minimum calibration constants.
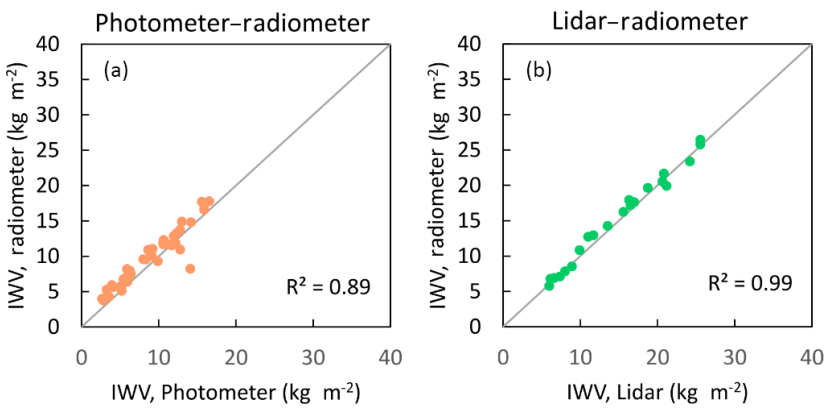

Figure 2. IWV intercomparison between different instruments: radiometer-sun photometer (a) and radiometer-lidar (b) with the $R^{2}$ coefficients provided.

have Raman lidar signals with SNR $>3$ in order to derive accurate integrated water vapor values. The agreement between lidar-derived IWV radiometer-derived IWV was very high $\left(R^{2}=0.98\right)$ as shown in Fig. 2 (right panel). Also the Raman lidar retrievals were not significantly biased from the microwave radiometer results. In most of the cases the absolute difference between the IWV values derived from these two instruments was not higher than 1 . We therefore inferred that the Raman lidar calibration can be considered reliable and the system is suitable to perform accurate water vapor mixing ratio measurements.
We performed another intercomparison to validate both WRF simulations and instrumental measurements of water vapor. We analyze the absolute difference (\%) between high-resolution radiosonde observations and each measurement and simulation technique (lidar, microwave radiometer, WRF simulations) separately. From Fig. 3 we can see that in the lowest tropospheric layer, lidar demonstrates the poorest agreement with radiosounding measurements due to incomplete geometrical overlap of the signal. In the lowest $500 \mathrm{~m}$, the median difference between radiosounding and lidar water vapor measurements is $151.6 \%$. Previous studies have shown that the overlap region of the EOLE system is around $300 \mathrm{~m}$ (Kokkalis et al., 2012). However, when water vapor parameters are retrieved, the overlap issue may affect lidar measurements between 500 and $1000 \mathrm{~m}$ due to different overlap characteristics of the Raman channels at 387 and $407 \mathrm{~nm}$. So, we investigated the bottom layer for lidar water vapor measurements for our study by averaging the radiosounding mixing ratios from 7 days and calculated the standard deviation from the mean water vapor mixing ratio value. The resultant standard deviation (0.58) is used to apply the data quality test. We set the altitude threshold based on 3 standard deviation so that heights where the mean difference between lidar and radiosounding data exceeded 1.74 are not used. Based on this analysis we determined the bottom height of $750 \mathrm{~m}$, above which the lidar measurements 


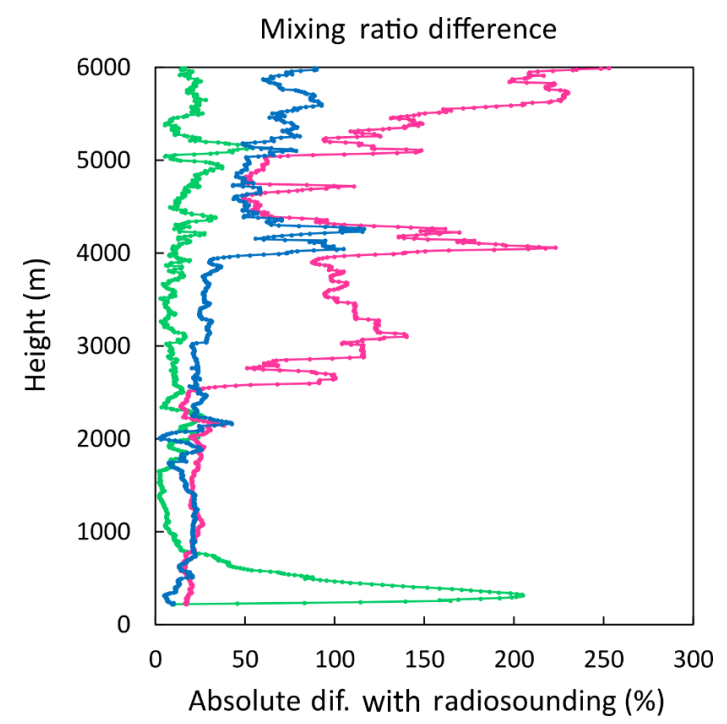

Figure 3. Absolute difference (\%) between the mixing ratio of water vapor from radiosoundings and lidar (green), microwave radiometer (red) and WRF simulations (blue). All six high-resolution radiosounding cases from the HygrA-CD campaign are used $(15,17$, 18, 20, 21 May and 1 June).

of the mixing ratio can be accurate enough to be used for $\mathrm{RH}$ retrievals. Then, when we analyze the agreement with radiosounding measurements between 750 and $6000 \mathrm{~m}$, lidar shows the best results. Lidar-radiosounding median difference is $11.8 \%$, while WRF-radiosounding median difference equals $28.6 \%$ and radiometer-radiosounding median difference reaches $86.6 \%$ (Fig. 3). As expected, the radiometer demonstrates reasonable agreement with reference radiosoundings only in the lowest $4000 \mathrm{~m}$ since above this layer, only $5 \%$ of retrieved observations originate from the radiometer itself.

\subsection{Evaluation of temperature profiles}

We analyzed the agreement and systematic bias of the available atmospheric temperature profiles compared to the 6 high-resolution radiosondes data, mentioned in the previous section. Only MWR (microwave radiometer) and WRF model simulations were applied, since the EOLE lidar system is not capable of temperature measurements. Just like humidity, physical temperature in the atmosphere is related to the brightness temperature of the object. Therefore, the basic principle of temperature retrieval by the radiometer is close to an analogical principle as applied to humidity profiling. Temperature varies vertically at the same rate for both radiometer measurements and model simulations for the considered dates, and there is no strong inversion by any instrument or simulation. Both the WRF model simulations and MWR measurements show high agreement with radiosoundings $\left(R^{2}=0.99\right.$ and 0.98 , respectively). However, some minor temperature inversions measured by the radiosoundings are not retrieved by the WRF model or the radiometer measurements (Fig. 4). For most of the cases, the agreement between the WRF model simulations and radiosoundings is better than the agreement between microwave radiometer and radiosoundings. In particular, the difference of temperatures between WRF model simulations and radiosoundings does not exceed $2{ }^{\circ} \mathrm{C}$ in the lowest region of the troposphere. WRF-radiosounding mean absolute bias $\left(0.45^{\circ} \mathrm{C}\right)$ is lower than radiometer-radiosounding mean absolute bias $\left(1.84^{\circ} \mathrm{C}\right)$. Radiometer results meet our expectations, according to Sect. 2.3, as the random error of temperature equals $1.7^{\circ} \mathrm{C}$. Considering the very high statistical agreement between radiometer and WRF simulations with radiosoundings, the low systematic bias and the fair agreement with literature values for the radiometer, we further used these temperature datasets as input observations for RH calculation. The role of the temperature uncertainty effects in resulting RH vertical profiling techniques are considered in the Sect. 4.2.3.

\section{Combined algorithms of relative humidity vertical profiling: lidar-radiometer and lidar-WRF methods}

We used two combined algorithms of RH vertical profiling: lidar-radiometer and lidar-WRF methods. The basics of RH calculations are explained below and presented along with description of both methods.

\subsection{Lidar-radiometer combination for relative humidity vertical profiling}

The synergistic lidar-radiometer method (LD-MWR hereafter) is based on two input datasets. The first input dataset is based on lidar measurements of the water vapor mixing ratio. The second input dataset is taken from water vapor and temperature measurements from the radiometer. AH profiles for lidar are calculated from a simple conversion formula in which mixing ratio profiles are multiplied with air density profiles (taken from the US Standard Atmosphere). We separated the atmospheric column into three different regions. The range of heights in lowest region $(0-750 \mathrm{~m})$ is dictated by lidar overlap limitations and only radiometer measurements are applied below $750 \mathrm{~m}$. In the middle region $(750$ $2000 \mathrm{~m}$ ) we combined mixing ratio measurements from the lidar with temperature and humidity measurements from the microwave radiometer in order to retrieve combined measurements of RH. The radiometer-retrieved RH profiles are interpolated to lidar measurements and then averaged with appropriate lidar measurements, which resulted in combined $\mathrm{RH}$ profiles. The combination acts to smooth the transition from the region where lidar is "blind" to the region where only lidar is used for water vapor measurements $(>2000 \mathrm{~m})$. In order to retrieve the $\mathrm{RH}$ profile, we calculate the saturation density of water vapor $\left(e_{\mathrm{s}}\right)$ (Eq. 3a) which can be defined 

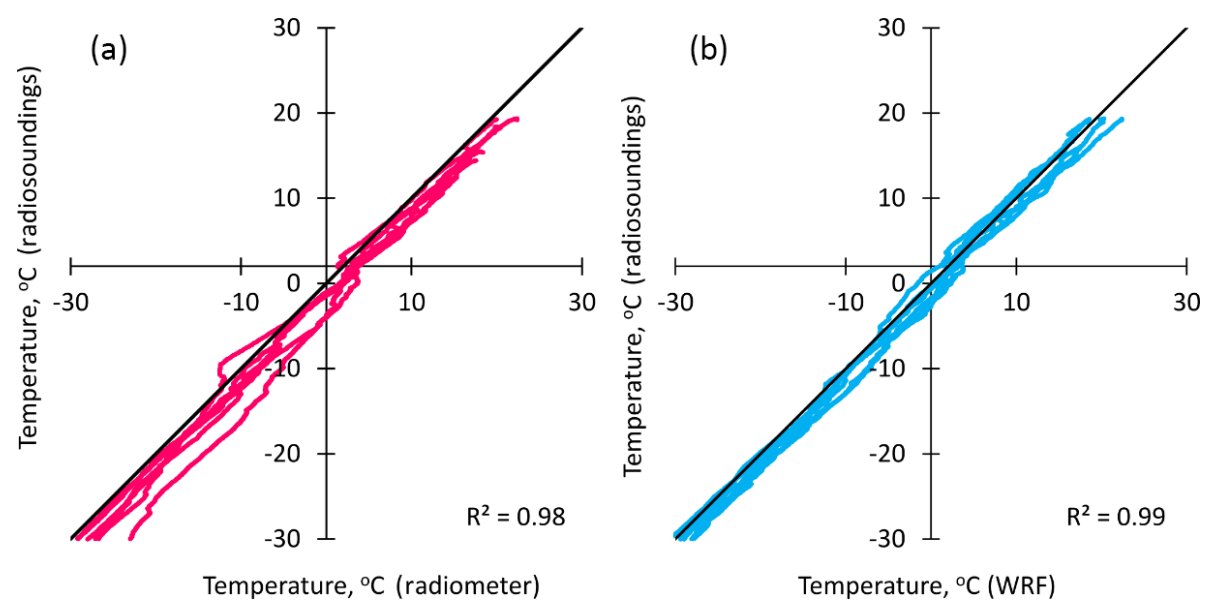

Figure 4. Temperature profiles intercomparison for all heights. All six high-resolution radiosounding cases from the HygrA-CD campaign are used (15, 17, 18, 20, 21 May and 1 June): radiosoundings versus radiometer (a, red) and radiosoundings versus WRF model simulations (b, blue).

as the ratio between the molecular mass of water $(M=18 \mathrm{~g})$ and gaseous constant of water vapor $(R=0.0623)$ multiplied by the atmospheric temperature $(T)$ taken from radiometer observations at the appropriate heights. Then, the ratio between $(M)$ and $(R T)$ is multiplied by the empirical value of the water vapor density $\left(p_{\mathrm{s}}\right)$, the calculation of which implies the use of temperature $(T)$ as well (Eq. $3 b)$.

$$
\begin{aligned}
& e_{\mathrm{s}}=\frac{M}{R T} \cdot p_{\mathrm{s}}(T) \\
& p_{\mathrm{s}}=(0.61078 \cdot 7.501) e^{\frac{17.2694 \cdot T}{238.3+T}}
\end{aligned}
$$

RH calculation includes the implementation of a simple conversion formula as the ratio between AH from lidar and saturation vapor density calculated from Eq. (3a).

\subsection{Lidar-WRF combination for relative humidity vertical profiling}

Using the lidar-WRF (LD-WRF) combined method for RH profiling we apply the same principles and formulas of the $\mathrm{RH}$ calculation as for the LD-MWR method. One difference is that instead of microwave radiometer measurements, we use WRF simulations in the same three layers of the troposphere chosen for analysis. Both synergetic methods are used simultaneously and compared with collocated radiosoundings.

\subsection{Evaluation of the relative humidity profiles}

\subsubsection{Microwave radiometer and WRF simulations versus high-resolution radiosounding}

We determine the effectiveness of each considered RH vertical profiling method and examine radiometer measurements (MWR), WRF model simulations, LD-MWR and LD-WRF methods. At first, only MWR and WRF model simulations are analyzed versus RH vertical profiles calculated from radiosoundings (Fig. 5). In some cases, MWR measurements do not depict some finer-scale humidity features in the middle troposphere (18 and 21 May, 1 June). The results are somewhat ambiguous in the first $1000 \mathrm{~m}$ where the agreement between radiosoundings with MWR or WRF simulations depend on every case. No clear pattern is identified to see whether MWR or WRF simulations agree with the radiosoundings or not. For instance, the agreement with radiosoundings is very similar for MWR and the WRF model in the case of 15 and 20 May, where the difference for both techniques does not exceed $10 \%$ between 100 and $1000 \mathrm{~m}$. Moreover, some higher humidity layers detected by radiosondes are not seen by both MWR measurements and WRF simulations (20 May, at $4500 \mathrm{~m}, 21$ May at $5000 \mathrm{~m}$, 1 June between 4000 and $5000 \mathrm{~m}$ ). These deficiencies that are indirectly seen from the bias calculation can be alleviated by addressing the combined algorithms.

\subsubsection{Synergetic methods versus high-resolution radiosounding}

The LD-MWR and LD-WRF methods are intercompared to the RH vertical profiling provided by high resolution radiosoundings and the results are shown for 6 days (15 May to 1 June). In general, both methods agree quite well with the radiosonde data from 1000 to $6000 \mathrm{~m}$ height; however, significant differences are evidenced. For example on 15 and 17 May the differences of both methods to the radiosonde data remain quite large between 500 and $3000 \mathrm{~m}$. On 20 and 21 May the agreement of both methods with the RH radiosonde data is very good in the height region from 1000 to $6000 \mathrm{~m}$. Finally, on 1 June both methods show the best agreement with the radiosonde data. In Tables 2 and 3 the ef- 

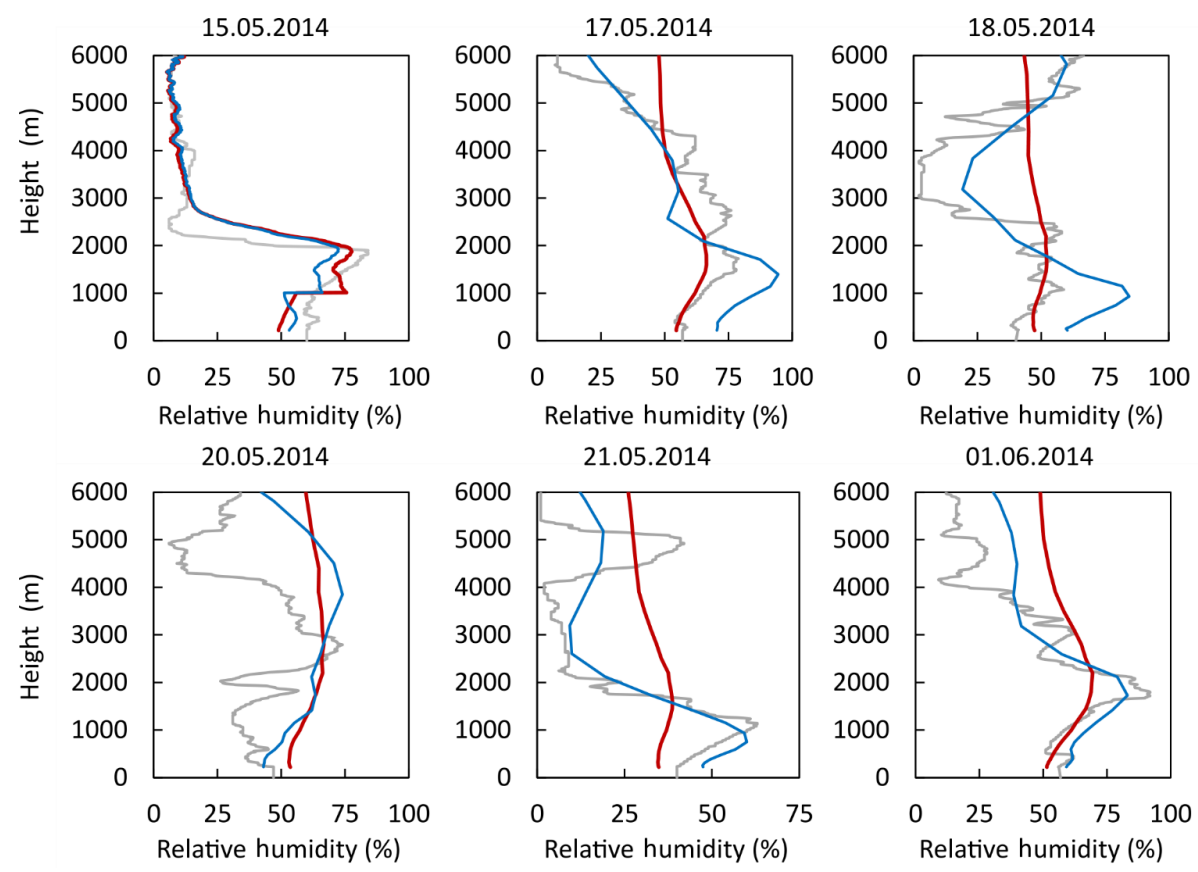

Figure 5. Vertical profiles of relative humidity from WRF model simulations (blue), microwave radiometer (red) and radiosoundings (grey).

Table 2. Determination coefficients $\left(R^{2}\right)$ between various measurements techniques or simulations of relative humidity profiling and highresolution radiosounding for different height regions. LD: lidar, MWR: microwave radiometer, WRF: WRF model.

\begin{tabular}{|c|c|c|c|c|c|c|c|c|c|c|c|c|}
\hline \multirow{2}{*}{$\begin{array}{l}R^{2} \\
\text { Height regions }\end{array}$} & \multicolumn{3}{|c|}{ MWR } & \multicolumn{3}{|c|}{ WRF } & \multicolumn{3}{|c|}{ LD-MWR } & \multicolumn{3}{|c|}{ LD-WRF } \\
\hline & Low & Mid. & Full & Low & Mid. & Full & Low & Mid. & Full & Low & Mid. & Full \\
\hline 15 May & 0.79 & 0.79 & 0.82 & 0.55 & 0.82 & 0.86 & 0.79 & 0.91 & 0.91 & 0.55 & 0.92 & 0.82 \\
\hline 17 May & 0.88 & 0.78 & 0.78 & 0.92 & 0.81 & 0.77 & 0.88 & 0.95 & 0.94 & 0.92 & 0.96 & 0.91 \\
\hline 18 May & 0.86 & 0.20 & 0.21 & 0.94 & 0.82 & 0.77 & 0.86 & 0.92 & 0.91 & 0.94 & 0.92 & 0.85 \\
\hline 20 May & 0.52 & 0.58 & 0.32 & 0.40 & 0.21 & 0.21 & 0.52 & 0.91 & 0.88 & 0.40 & 0.90 & 0.88 \\
\hline 21 May & 0.96 & 0.91 & 0.88 & 0.89 & 0.84 & 0.87 & 0.96 & 0.91 & 0.87 & 0.89 & 0.91 & 0.93 \\
\hline 1 June & 0.27 & 0.94 & 0.87 & 0.05 & 0.90 & 0.90 & 0.27 & 0.96 & 0.96 & 0.05 & 0.90 & 0.90 \\
\hline Mean & 0.71 & 0.70 & 0.65 & 0.63 & 0.73 & 0.73 & 0.71 & 0.93 & 0.92 & 0.63 & 0.92 & 0.88 \\
\hline
\end{tabular}

ficiency of these approaches is further analyzed by addressing a statistical analysis of the datasets obtained.

We calculated the $R^{2}$ and the resulting mean bias of RH vertical profiling obtained by each technique and the radiosonde data (Tables 2 and 3). The $R^{2}$ values for the combined methods are obviously similar to the associated single methods (e.g., LD-MWR with radiometer and LD-WRF with WRF model simulations) in the lowest region. Interestingly, analysis of the middle region shows that the use of lidar-derived humidity data in the combined methods drastically increases the agreement with radiosoundings in comparison to the MWR and WRF model simulations alone. For instance, the mean $R^{2}$ value between MWR and radiosoundings in this region is 0.70 , while the replacement of lowresolution humidity data from the MWR to lidar humidity data improves $R^{2}\left(R^{2}=0.93\right)$. However, the WRF model- simulated RH in the same region shows reasonable agreement with radiosounding data $\left(R^{2}=0.73\right)$. The agreement increases when we combine WRF model-simulated temperature and lidar mixing ratio in this region $\left(R^{2}=0.92\right)$. Both examples demonstrate that the role of the lidar data becomes more effective in heights above $1000 \mathrm{~m}$ in combination with measurement data (modeling data) obtained (simulated) within the PBL. The highest $R^{2}$ values $\left(R^{2}=0.92\right)$ in the full considered tropospheric column are observed when the LD-MWR method is used.

The radiometer shows the lowest mean bias (7.09) in the low region, while the WRF model shows a poorer agreement with radiosoundings (12.32). We observe a significant improvement in the middle and full region when we address the combined algorithms. For example, the microwave radiometer when used alone shows a mean bias of 13.63 and 11.61 

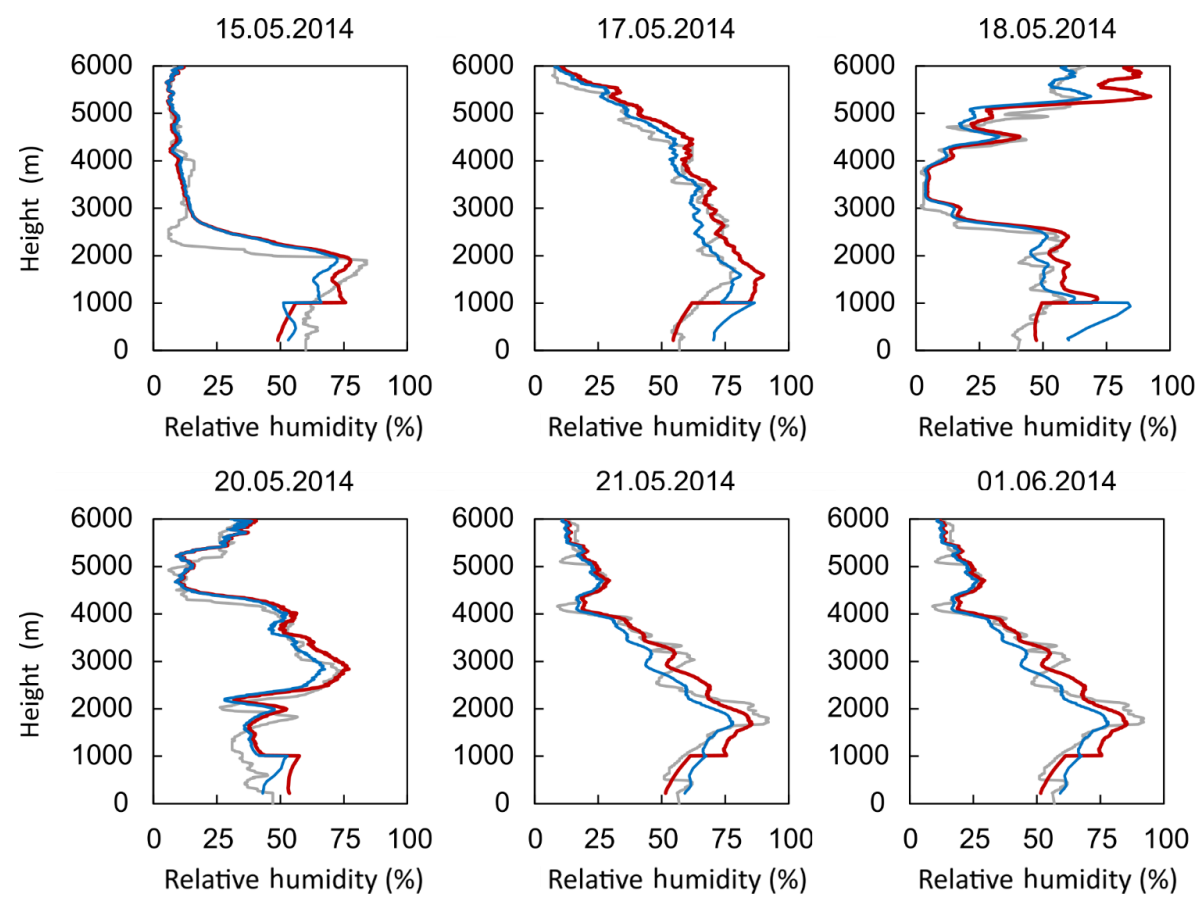

Figure 6. Vertical profiles of RH from combined methods for LD-WRF (blue) and LD-MWR (red) against high-resolution radiosoundings (grey).

in middle and full region, respectively, while the LD-MWR combined method decreases the mean bias to 4.08 and 3.37, respectively. A similar improvement is noted with the WRF model simulations as well. Alone, the WRF model-simulated RH shows mean biases of 7.50 in the middle region and 7.44 in the full region. The synergistic use of lidar water vapor data in the full region decreases the mean biases down by nearly $75 \%$ to the value of 1.29 in the middle region and 1.73 in the full region.

\subsubsection{Synergetic methods versus low-resolution radiosounding}

At last we apply both synergetic methods in the comparison against the low-resolution radiosounding data, when highresolution radiosoundings were not available. The LD-MWR and the LD-WRF method show a $R^{2}$ value of 0.66 and 0.65 , respectively, for heights between 100 and $6000 \mathrm{~m}$. The agreement between the combined methods of $\mathrm{RH}$ profiling and radiosoundings is again quite satisfactory for the June period, as presented in Fig. 7. However, some disagreement is found between 2500 and $4000 \mathrm{~m}$ on 2 June, and between 100 and $1500 \mathrm{~m}$ on 12 June, probably due to missing data from the radiosonde.

We calculated again the $R^{2}$ values between each method of RH profiling (MWR, WRF model simulations, LD-MWR, LD-WRF) against low-resolution radiosoundings (Table 4). In the lowest region the WRF-based methods show the highest agreement with radiosoundings. The $R^{2}$ for both separate
WRF simulations and LD-WRF method equals 0.70 , while $R^{2}$ for the MWR-based measurements equals 0.59 for both cases (MWR and LD-MWR). In the middle region, the use of lidar data contributes to an improvement in the agreement with radiosounding for both MWR and WRF methods. In this case the MWR-related $R^{2}$ is improved from 0.54 (MWR) to 0.68 (LD-MWR) and the WRF-related $R^{2}$ is increased from 0.62 (only WRF) to 0.71 (LD-WRF). In addition, if we ignore two cases where the lidar signal was noisy, the LDMWR agreement remarkably improves $\left(R^{2}=0.76\right)$, while the radiometer alone remains nearly constant $\left(R^{2}=0.55\right)$. Finally, if we consider all the heights from 100 to $6000 \mathrm{~m}$ one can summarize that both combined methods (LD-MWR and LD-WRF) show the highest statistical agreement in comparison with single methods. The $R^{2}$ value of LD-MWR equals 0.66 in this case (and is up to 0.73 when the noisy lidar data are not taken into account), while the use of radiometer data alone results in a mean $R^{2}$ of only 0.49 for these heights. The LD-WRF method has a $R^{2}$ value of 0.66 at these heights ( 0.73 if lidar noisy data are excluded), while the WRF model simulations alone result in similar $R^{2}$ values $(0.65)$. The uncertainties of RH profiles associated with temperature variability are discussed in detail for both methods in Sect. 4.4. 
Table 3. Mean bias between various measurements techniques or simulations of relative humidity vertical profiling and high-resolution radiosounding measurements for different height regions. LD: lidar, MWR: microwave radiometer, WRF: WRF model.

\begin{tabular}{|c|c|c|c|c|c|c|c|c|c|c|c|c|}
\hline \multirow{2}{*}{$\begin{array}{l}\text { Mean bias } \\
\text { Height regions }\end{array}$} & \multicolumn{3}{|c|}{ MWR } & \multicolumn{3}{|c|}{ WRF } & \multicolumn{3}{|c|}{$\mathrm{LD}+\mathrm{MWR}$} & \multicolumn{3}{|c|}{$\mathrm{LD}+\mathrm{WRF}$} \\
\hline & Low & Mid. & Full & Low & Mid. & Full & Low & Mid. & Full & Low & Mid. & Full \\
\hline 15 May & 9.20 & 15.30 & 11.95 & 7.60 & 2.29 & 0.93 & 9.20 & 3.44 & 1.71 & 7.60 & 2.20 & 0.85 \\
\hline 17 May & 1.29 & 0.59 & 0.33 & 17.11 & 1.31 & 1.21 & 1.29 & 6.42 & 5.35 & 17.11 & 0.09 & 2.42 \\
\hline 18 May & 2.49 & 12.88 & 11.45 & 27.98 & 8.18 & 10.90 & 2.49 & 6.88 & 6.27 & 27.98 & 0.98 & 2.99 \\
\hline 20 May & 15.6 & 24.22 & 23.00 & 8.85 & 24.31 & 22.19 & 15.60 & 2.97 & 4.70 & 8.85 & 0.50 & 0.78 \\
\hline 21 May & 13.6 & 13.77 & 10.00 & 6.06 & 1.68 & 2.28 & 13.69 & 2.94 & 0.66 & 6.06 & 0.65 & 1.39 \\
\hline 1 June & 0.30 & 15.06 & 12.96 & 6.33 & 7.27 & 7.14 & 0.30 & 1.88 & 1.58 & 6.33 & 3.32 & 2.00 \\
\hline Mean & 7.09 & 13.63 & 11.61 & 12.32 & 7.50 & 7.44 & 7.09 & 4.08 & 3.37 & 12.32 & 1.29 & 1.73 \\
\hline
\end{tabular}
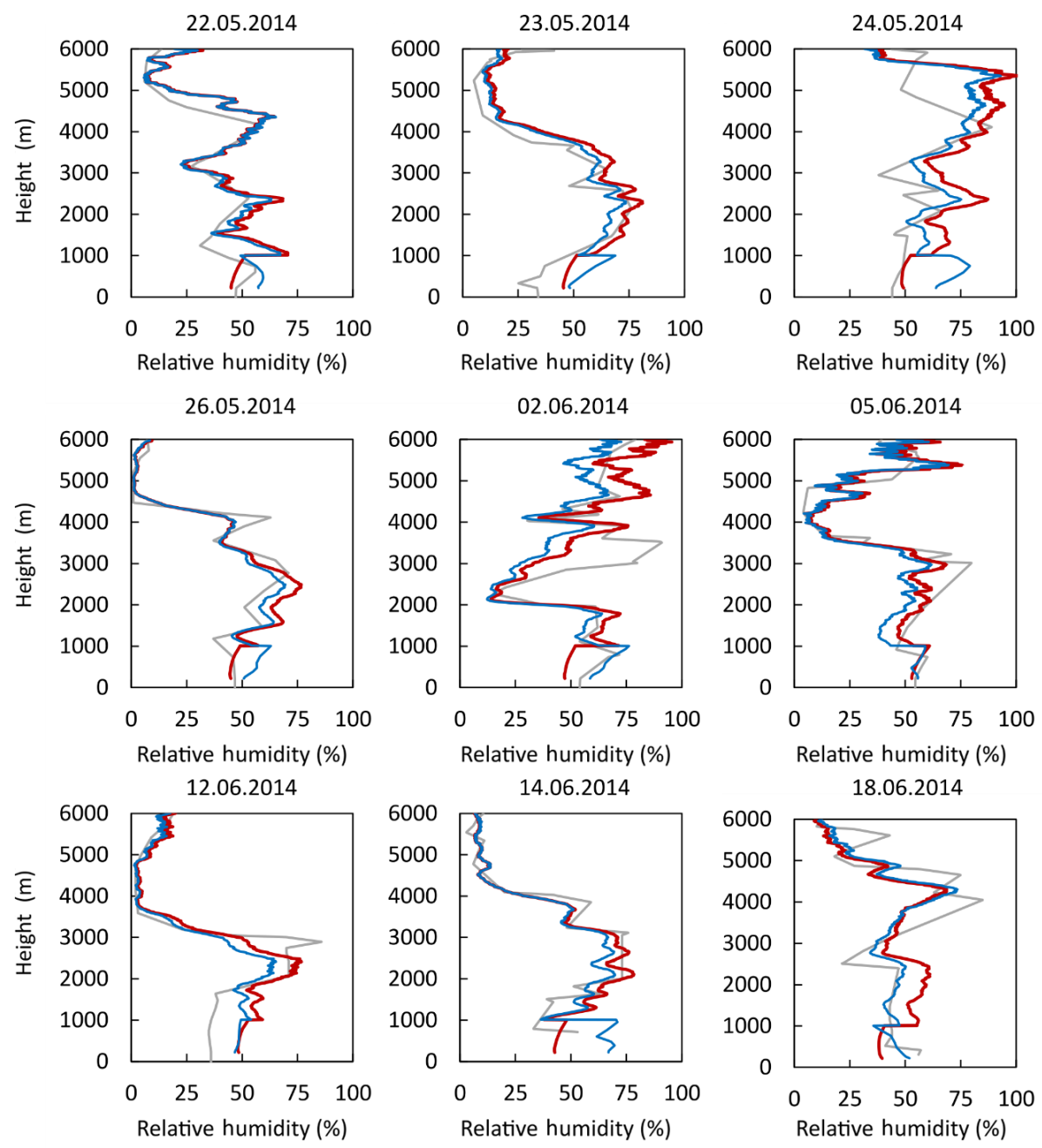

Figure 7. Vertical profiles of RH from combined methods: LD-WRF (blue) and LD-MWR (red) versus radiosounding (grey) for the dates when only low-resolution radiosoundings are available during June 2014. 
Table 4. Determination coefficients between various measurements techniques or simulations of relative humidity profiling and radiosounding for different height regions (low-resolution radiosounding cases). LD: lidar, MWR: microwave radiometer, WRF: WRF model.

\begin{tabular}{|c|c|c|c|c|c|c|c|c|c|c|c|c|}
\hline \multirow{2}{*}{$\begin{array}{l}\text { Det. coef. } \\
\text { Height regions }\end{array}$} & \multicolumn{3}{|c|}{ MWR } & \multicolumn{3}{|c|}{ WRF } & \multicolumn{3}{|c|}{$\mathrm{LD}+\mathrm{MWR}$} & \multicolumn{3}{|c|}{$\mathrm{LD}+\mathrm{WRF}$} \\
\hline & Low & Mid. & Full & Low & Mid. & Full & Low & Mid. & Full & Low & Mid. & Full \\
\hline 22 May & 0.34 & 0.63 & 0.62 & 0.70 & 0.76 & 0.75 & 0.34 & 0.85 & 0.82 & 0.70 & 0.85 & 0.87 \\
\hline 23 May & 0.95 & 0.88 & 0.77 & 0.95 & 0.92 & 0.93 & 0.95 & 0.97 & 0.97 & 0.95 & 0.97 & 0.94 \\
\hline 24 May & 0.77 & 0.44 & 0.53 & 0.83 & 0.18 & 0.76 & 0.77 & 0.34 & 0.45 & 0.83 & 0.35 & 0.11 \\
\hline $25 \mathrm{May}^{\mathrm{a}}$ & - & 0.19 & 0.28 & - & 0.76 & 0.75 & - & 0.34 & 0.33 & - & 0.36 & 0.35 \\
\hline 26 May & 0.96 & 0.89 & 0.70 & 0.87 & 0.90 & 0.89 & 0.96 & 0.96 & 0.96 & 0.87 & 0.97 & 0.96 \\
\hline $28 \mathrm{May}^{\mathrm{a}}$ & 0.20 & 0.78 & 0.67 & 0.61 & 0.37 & 0.40 & 0.20 & 0.22 & 0.30 & 0.61 & 0.29 & 0.34 \\
\hline 2 June & 0.68 & 0.46 & 0.44 & 0.74 & 0.56 & 0.54 & 0.68 & 0.62 & 0.61 & 0.74 & 0.61 & 0.58 \\
\hline 5 June & 0.64 & 0.56 & 0.54 & 0.62 & 0.68 & 0.67 & 0.64 & 0.89 & 0.64 & 0.62 & 0.89 & 0.87 \\
\hline 12 June & 0.22 & 0.10 & 0.14 & 0.44 & 0.81 & 0.77 & 0.22 & 0.93 & 0.92 & 0.44 & 0.92 & 0.89 \\
\hline 14 June & 0.59 & 0.88 & 0.89 & 0.68 & 0.84 & 0.78 & 0.59 & 0.96 & 0.96 & 0.68 & 0.97 & 0.92 \\
\hline 15 June & 0.91 & 0.21 & 0.04 & 0.66 & 0.13 & 0.05 & 0.91 & 0.55 & 0.40 & 0.66 & 0.56 & 0.31 \\
\hline 18 June & 0.24 & 0.43 & 0.29 & 0.55 & 0.51 & 0.50 & 0.24 & 0.56 & 0.55 & 0.55 & 0.72 & 0.72 \\
\hline Mean & 0.59 & 0.54 & 0.49 & 0.70 & 0.62 & 0.65 & 0.59 & 0.68 & 0.66 & 0.70 & 0.71 & 0.66 \\
\hline
\end{tabular}

a Days when the lidar signal-to-noise ratio is not high enough in the middle troposphere.

Table 5. Mean and maximum absolute uncertainty of RH synergetic retrieval for two combined methods (lidar-radiometer and lidar-WRF) for different height regions. Data from 25 May are excluded from this analysis due to the signal-to-noise ratio. The lidar system is registered to adequately assess the uncertainties resulting from final RH profiles for this day.

\begin{tabular}{|c|c|c|c|c|c|c|c|c|c|c|c|c|}
\hline \multirow{2}{*}{$\begin{array}{l}\text { Uncertainties } \\
\text { Height regions }\end{array}$} & \multicolumn{3}{|c|}{ LD + MWR (mean) } & \multicolumn{3}{|c|}{ LD + WRF (mean) } & \multicolumn{3}{|c|}{ LD + MWR (max.) } & \multicolumn{3}{|c|}{ LD + WRF (max.) } \\
\hline & Low & Mid. & Full & Low & Mid. & Full & Low & Mid. & Full & Low & Mid. & Full \\
\hline 15 May & 2.63 & 3.41 & 2.59 & 1.62 & 0.79 & 0.90 & 2.67 & 9.51 & 9.51 & 1.99 & 2.15 & 2.15 \\
\hline 17 May & 2.94 & 8.05 & 6.56 & 2.00 & 1.73 & 1.76 & 2.79 & 10.86 & 10.86 & 2.16 & 2.36 & 2.36 \\
\hline 18 May & 2.43 & 5.42 & 4.36 & 1.79 & 1.03 & 1.13 & 2.27 & 13.34 & 13.34 & 2.17 & 2.32 & 2.32 \\
\hline 20 May & 3.00 & 5.36 & 4.22 & 1.22 & 1.19 & 1.19 & 1.62 & 9.49 & 9.49 & 1.37 & 1.99 & 1.99 \\
\hline 21 May & 1.58 & 2.58 & 2.02 & 1.55 & 0.55 & 0.69 & 2.22 & 8.16 & 8.16 & 1.84 & 1.88 & 1.88 \\
\hline 22 May & 2.25 & 5.12 & 4.12 & 1.67 & 1.19 & 1.26 & 2.40 & 8.60 & 8.60 & 2.03 & 2.10 & 2.10 \\
\hline 23 May & 2.44 & 5.70 & 4.60 & 1.39 & 1.24 & 1.26 & 1.75 & 9.62 & 9.62 & 1.63 & 2.11 & 2.11 \\
\hline 24 May & 2.50 & 9.33 & 7.73 & 1.78 & 2.00 & 1.97 & 1.91 & 14.08 & 14.08 & 2.12 & 3.11 & 3.11 \\
\hline 26 May & 2.26 & 4.62 & 3.68 & 1.46 & 1.06 & 1.11 & 1.81 & 8.98 & 8.98 & 1.56 & 1.97 & 1.97 \\
\hline 28 May & 1.41 & 6.33 & 5.29 & 0.95 & 1.57 & 1.49 & 1.35 & 13.81 & 13.81 & 1.09 & 4.25 & 4.25 \\
\hline 1 June & 2.77 & 5.70 & 4.56 & 1.71 & 1.21 & 1.28 & 2.48 & 10.06 & 10.06 & 1.89 & 2.23 & 2.23 \\
\hline 2 June & 2.33 & 7.46 & 6.13 & 1.79 & 1.43 & 1.47 & 2.82 & 14.33 & 14.33 & 2.08 & 2.54 & 2.54 \\
\hline 5 June & 2.94 & 5.24 & 4.13 & 1.40 & 1.12 & 1.16 & 1.97 & 10.85 & 10.85 & 1.55 & 2.38 & 2.38 \\
\hline 10 June & 3.51 & 5.51 & 4.28 & 1.58 & 1.17 & 1.22 & 2.43 & 8.92 & 8.92 & 1.85 & 1.92 & 1.92 \\
\hline 12 June & 2.48 & 3.73 & 2.88 & 1.33 & 0.77 & 0.85 & 1.92 & 9.01 & 9.01 & 1.53 & 1.84 & 1.84 \\
\hline 14 June & 2.31 & 4.82 & 3.85 & 1.54 & 1.10 & 1.16 & 1.40 & 8.97 & 8.97 & 1.84 & 1.98 & 1.98 \\
\hline 15 June & 2.53 & 7.47 & 6.12 & 1.37 & 1.84 & 1.78 & 2.08 & 9.42 & 9.42 & 1.70 & 2.25 & 2.25 \\
\hline 18 June & 1.86 & 5.28 & 4.31 & 1.22 & 1.21 & 1.21 & 1.63 & 8.72 & 8.72 & 1.35 & 2.29 & 2.29 \\
\hline Abs. mean & 2.45 & 5.46 & 4.34 & 1.55 & 1.19 & 1.22 & & & & & & \\
\hline Max & & & & & & & 2.82 & 14.33 & 14.33 & 2.17 & 4.25 & 4.25 \\
\hline
\end{tabular}

\subsection{Role of temperature random error in relative humidity vertical profiling based on lidar-radiometer and lidar-WRF methods}

Points of measurements were not depicted in Figs. 5, 6 and 7 since all measurements and simulations are interpolated to high-resolution measurements of water vapor mixing ratio. Error bars were also not shown since it is challenging to compare instrumental-related errors from radiometer brightness temperature noise and WRF-model systematic errors. To alleviate such gaps and to conclude our analysis we examine the uncertainties of each synergistic RH vertical pro- 
filing method. The largest uncertainties in synergetic methods can be most likely caused by the errors in temperature input. For the MWR we take temperature systematic bias values from the literature as described in Sect. 2.3. Due to the difference in the performance of the radiometer at different altitudes, as shown before, we use a random error of $0.5^{\circ} \mathrm{C}$ in the altitudes below $1000 \mathrm{~m}$ and $1.7^{\circ} \mathrm{C}$ in the layers above $1000 \mathrm{~m}$. Since WRF model uncertainties cannot be addressed in the same manner as the radiometer random error, we use for the WRF-simulation radiosounding a mean absolute bias of $0.45^{\circ} \mathrm{C}$ from our results (shown in Sect. 3.3) to use as temperature random error in our simulations. Therefore, we calculate the RH profiles based on both combined methods with different temperature inputs (minimum, mean and maximum according to abovementioned temperature random errors) where minimum and maximum temperatures are used to calculate the minimum and maximum $\mathrm{RH}$ values for each method. In such a manner, difference between the resulting maximum and minimum $\mathrm{RH}$ represents the final uncertainty of our RH profiling due to temperature random errors. When low tropospheric layers are considered, as we expected, the synergetic methods show improved performance as the temperature variations are not high for both MWR and WRF simulations. As a result, the LD-MWR method results in a mean uncertainty of $2.45 \%$ of RH due to temperature variations, where the RH uncertainty does not exceed $2.82 \%$ in the lowest layer for LD-WRF, respectively. The LD-WRF method in the lowest layer results in a mean uncertainty of $1.55 \%$ for the RH vertical profiling where the maximum possible uncertainty equals $2.17 \%$. The RH results show higher discrepancies in the layer between 1000 and $6000 \mathrm{~m}$ for the LD-MWR method due to an increased temperature-related error propagation. The mean LD-MWR uncertainty of RH profiling in this layer is $5.46 \%$. Meanwhile, the LD-WRF method shows high performance in the middle layer based on a calculated mean uncertainty of RH equals $1.19 \%$. The results of both methods seem reasonable based on the mean values of RH uncertainties. However, by analyzing the maximum uncertainty of RH we can see that temperature deviations in input data may affect our RH vertical profiles very significantly. For instance, when radiometer temperatures input varies by $1.7^{\circ} \mathrm{C}$, we face larger error propagations (of the order of $10 \%$ ) in the middle troposphere observations (see Table 5). Despite this, average uncertainties for both LDMWR and LD-WRF are reasonable, and some atmospheric layers can still be reconstructed with rather high uncertainties in RH (maximum can reach $14.33 \%$ for LD-MWR). This phenomenon is evidently not seen in the LD-WRF method, as we assumed a temperature simulation uncertainty to be uniform and rather low along the atmospheric column. Considering this assumption, the resulting uncertainties from $\mathrm{RH}$ profiling using the LD-WRF method in the middle troposphere does not exceed $4.25 \%$. We also analyze full considered atmospheric height from 100 to $6000 \mathrm{~m}$. Here LD-WRF shows quite accurate $\mathrm{RH}$ profiling performance; average un- certainty of RH resulting from temperature error propagation is $1.22 \%$ and maximum is $4.25 \%$. The LD-MWR method shows reasonable results according to the mean uncertainties $(4.34 \%)$ for full considered heights; however, for some atmospheric layers the maximum uncertainty from this method was also high (of the order of $13 \%$ ).

\section{Conclusions}

In this study, we addressed two synergistic methods for RH vertical profiling based on combined lidar-radiometer and lidar-WRF datasets. The first method exploited water vapor mixing ratio profiles derived from lidar measurements in combination with temperature measurements from a collocated radiometer as input datasets for RH calculation. The second method combined water vapor mixing ratio profiles derived from Raman lidar data with high-resolution simulations from the WRF model. We showed the advantages and disadvantages of these methods for RH vertical profiling for case studies during the HygrA-CD campaign. We evaluated both methods according to current thermodynamic profiling requirements regarding accuracy, spatial resolution and measurement range analysis of observations. Prior to the main analysis, the EOLE Raman lidar system had been successfully calibrated for water vapor measurements by using collocated high-resolution radiosonde data and yielding an optimal calibration constant $(C=23.65 \pm 2.28)$. The sanity of the high-resolution calibration constant was checked by the comparison with a second calibration constant calculated from low-resolution radiosonde data $(C=24.36 \pm 2.14)$. The ability of each instrument to retrieve water vapor parameters has been checked via IWV intercomparison. IWV intercomparison showed very high agreement between all comparable instruments $\left(R^{2}=99\right.$ for lidar-radiometer and $R^{2}=0.89$ for sun photometer-radiometer).

We determined the lowest and the upper threshold heights for the water vapor vertical profiling using Raman lidar. Based on the absolute difference between the mean calibration constant $C$ and 3 standard deviation we concluded that below $750 \mathrm{~m}$ the combined methods should rely solely on radiometer observations and WRF simulations. The upper threshold layer for water vapor measurements has been determined accordingly at $6000 \mathrm{~m}$. In the atmospheric layer constrained by these boundaries $(750-6000 \mathrm{~m})$, the lidar water vapor retrievals are the most accurate and reliable. The use of high-resolution $(7.5 \mathrm{~m})$ water vapor measurements gave advantages in terms of resolution and accuracy for both synergetic methods between 1000 and $6000 \mathrm{~m}$. We exploited high-resolution collocated radiosoundings as a reference for our $\mathrm{RH}$ observations. In terms of accuracy, we demonstrated the significant improvement from single (radiometer or WRF simulations) to synergetic methods of RH profiling. The $R^{2}$ value between the WRF model alone and high-resolution radiosoundings was found to be 
equal to 0.73 , while the use of the LD-WRF method improved this agreement slightly $\left(R^{2}=0.88\right)$. Similarly, the use of the radiometer alone resulted in a mean $R^{2}$ of 0.65 against high-resolution radiosoundings, while the LD-MWR method showed remarkable improvement $\left(R^{2}=0.92\right)$. We observed a similar improvement by using the LD-MWR method when low-resolution radiosoundings were employed (launched for 12 days during the campaign). The mean $R^{2}$ value between radiometer RH profiles and low-resolution radiosounding RH profiles improved from 0.49 to 0.66 . When low-resolution radiosondes were used, the LD-WRF method did not show any improvement in comparison with RH standalone WRF model simulations. No improvement in this case stems rather from the lack of high-resolution reference measurements than from the issues associated with the combined method.

In order to understand the role of temperature variations in resulting $\mathrm{RH}$ profiles, we examined the temperature-related errors for both LD-MWR and LD-WRF methods. Temperature random errors for the radiometer were taken from the literature $\left( \pm 0.5^{\circ} \mathrm{C}\right.$ for $0-1000 \mathrm{~m}$ and $\pm 1.7^{\circ} \mathrm{C}$ for 1000 $6000 \mathrm{~m}$ ) and for WRF simulations from a systematic bias of $\pm 0.45^{\circ} \mathrm{C}$ calculated in our study. According to the mean RH uncertainties (between 100 and $6000 \mathrm{~m}$ ), both methods showed a good performance since the LD-WRF and LDMWR mean temperature-related uncertainties equal to 1.22 and to $4.34 \%$, respectively. However, in future studies, the mean uncertainties of the LD-MWR method should be carefully applied as the sources of systematic errors since LDMWR temperature-associated uncertainties in some cases may result in significant error propagation (up to $14.33 \%$ ).

During the HygrA-CD campaign, both combined methods showed an improved performance in terms of spatial resolution and accuracy in comparison to single observations and high-resolution WRF simulations. This improvement is remarkable in the height range between 1000 and $6000 \mathrm{~m}$. When RH observations are required, both combined methods can be valuable in terms of accuracy and spatial resolution of the measurements with reasonable limitations. In future studies, LD-MWR and LD-WRF methods can be beneficial for the steadily increasing number of atmospheric stations possessing both microwave radiometer and Raman lidar systems.

Data availability. The lidar data used in this study are available upon registration at http://data.earlinet.org.

Competing interests. The authors declare that they have no conflict of interest.

Acknowledgements. The authors thank the ITaRS program for generous support. The research leading to this article has received funding from the European Community's FP7 - PEOPLE 2011 under grant agreement number 289923 - ITARS (Initial Training for Atmospheric Remote Sensing) and has also been supported by the National Core Program - PN 16.40.01.01/2017 and ROSA STAR project CARESSE. All WRF simulations were performed on the MareNostrum supercomputer hosted by the Barcelona Supercomputing Center (BSC). We acknowledge the project CGL201346736-R, and the Severo Ochoa Programme awarded by the Spanish Government (SEV-2011-00067) and 2014 SGR 522. Additionally, the research leading to these results has received funding from the European Union's Horizon 2020 Research and Innovation programme under grant agreement no. 602014, project ECARS (East European Centre for Atmospheric Remote Sensing). The Hellenic National Meteorological Service (HNMS) is acknowledged for performing the high-resolution radiosoundings. We acknowledge the team from the University of Cologne for the microwave radiometer calibration and installation the HygrA-CD campaign. The financial support of the ACTRIS Research Infrastructure Project by the European Union's Horizon 2020 - Research and Innovation Framework Programme, under grant agreement no. 654169 is gratefully acknowledged.

The topical editor, Vassiliki Kotroni, thanks two anonymous referees for help in evaluating this paper.

\section{References}

Adam, M., Venable, D., Connell, R., Joseph, E., Whiteman, D. N., and Demoz, B. B.: Performance of the Howard University Raman Lidar during 2006 WAVES campaign, J. Optoelectron. Adv. M., 9, 3522-3528, 2007.

Altaratz, O., Bar-Or, R. Z., Wollner, U., and Koren, I.: Relative humidity and its effect on aerosol optical depth in the vicinity of convective clouds, Environ. Res. Lett., 8, 034025, https://doi.org/10.1088/1748-9326/8/3/034025, 2013

Arshinov, Y. F., Bobrovnikov, S. M., Zuev, V. E., and Mitev, V.: Atmospheric temperature measurements using a pure rotational Raman Lidar, Appl. Optics, 22, https://doi.org/10.1364/AO.22.002984, 1983.

Banks, R. F., Tiana-Alsina, J., Baldasano, J. M., Rocadenbosch, F., Papayannis, A., Solomos, S., and Tzanis, C. G.: Sensitivity of boundary-layer variables to PBL schemes in the WRF model based on surface meteorological observations, lidar, and radiosondes during the HygrA-CD campaign, Atmos. Res., 176177, 185-201, https://doi.org/10.1016/j.atmosres.2016.02.024, 2016

Barrera-Verdejo, M., Crewell, S., Löhnert, U., Orlandi, E., and Di Girolamo, P.: Ground-based lidar and microwave radiometry synergy for high vertical resolution absolute humidity profiling, Atmos. Meas. Tech., 9, 4013-4028, https://doi.org/10.5194/amt9-4013-2016, 2016.

Bucholtz, A.: Rayleigh-scattering calculations for the terrestrial atmosphere, Appl. Optics, 34, 2765-2777, https://doi.org/10.1364/AO.34.002765, 1995.

Charlson, R. J., Schwartz, S. E., Hales, J. M., Cess, R. D., Coakley Jr., J. A., Hansen, J. E., and Hoffman, J.: Climate forcing by antropogenic aerosols, Science New Series, 255, 423-430, 1992.

COESA: U.S. Standard Atmosphere, U.S. Gov. Print Off, Washington, D.C., 1976. 
Crewell, S., Czekala, H., Löhnert, U., Simmer, C., Rose, T., and Zimmerman, R.: Microwave radiometer for cloud carthography: A 22-channel ground-based microwave radiometer for atmospheric research, Radio Sci., 36, 621-638, 2001.

Dubovik, O. and King, M. D.: A flexible inversion algorithm for retrieval of aerosol optical properties from Sun and sky radiance measurements, J. Geophys. Res., 20, 20673-20696, 2000.

Dubovik, O., Sinyuk, A., Lapyonok, T., Holben, B. N., Mishchenko, M., Yang, P., Eck, T. F., Volten, H., Munoz, O., Veihelmann, B., van der Zande, W. J., Leon, J. F., Sorokin, M., and Slutsker, I.: Application of spheroid models to account for aerosol particle nonsphericity in remote sensing of desert dust, J. Geophys. Res., 111, D11208, https://doi.org/10.1029/2005JD006619, 2006.

Fan, J., Zhang, R., Li, G., Tao, W.-K., and Li, X.: Effects of aerosols and relative humidity on cumulus clouds, J. Geophys. Res., 112, D14204, https://doi.org/10.1029/2006JD008136, 2007.

Feltz, W. F., Smith, W. L., Knuteson, R. O., Revercomb, H. E., Woolf, H. M., and Howell, H. B.: Meteorological Applications of Temperature and Water Vapor Retrievals from the Groundbased atmospheric emitted radiance interferometer (AERI), J. Appl. Meteorol., 37, 857-875, 1998.

Foth, A., Baars, H., Di Girolamo, P., and Pospichal, B.: Water vapour profiles from Raman lidar automatically calibrated by microwave radiometer data during HOPE, Atmos. Chem. Phys., 15, 7753-7763, https://doi.org/10.5194/acp-15-7753-2015, 2015.

Goldsmith, J. E., Blair, F. H., Bisson, S. E., and Turner, D. D.: Turnkey Raman lidar for profiling atmospheric water vapor, clouds and aerosols, Appl. Optics, 37, 4979-4990, 1998.

Granados-Muñoz, M. J., Navas-Guzmán, F., Bravo-Aranda, J. A., Guerrero-Rascado, J. L., Lyamani, H., Valenzuela, A., Titos, G., Fernández-Gálvez, J., and Alados-Arboledas, L.: Hygroscopic growth of atmospheric aerosol particles based on active remote sensing and radiosounding measurements: selected cases in southeastern Spain, Atmos. Meas. Tech., 8, 705-718, https://doi.org/10.5194/amt-8-705-2015, 2015.

Güldner, J.: A model-based approach to adjust microwave observations for operational applications: results of a campaign at $\mathrm{Mu}-$ nich Airport in winter 2011/2012, Atmos. Meas. Tech., 6, 28792891, https://doi.org/10.5194/amt-6-2879-2013, 2013.

Hanel, G. and Zankl, B.: Aerosol size and relative humidity: Water uptake bymixtures of salts, Tellus, 31, 478-486, 1979.

Hegg, D. A., Covert, D. S., Rood, M. J., and Hobbs, P. V.: Measurements of aerosol optical properties in marine air, J. Geophys. Res., 101, 12893-12903, 1996.

Held, I. M. and Soden, B. J.: Water vapor feedback and global warming, Annu. Rev. Energy Environ., 25, 441-475, 2000.

Hogg, D., Decker, M., Guiraud, F., Earnshaw, K., Merritt, D., Moran, K., Sweezy, W., Strauch, R., Westwater, E., and Little, G.: An automatic Profiler of the Temperature, Wind and Humidity in the Troposphere, J. Appl. Meteorol., 22, 807-831, 1983.

Holben, B. N., Eck, T. F., Slutsker, I., Tanre, D., Buis, J. P., Setzer, A., Vermote, E., Reagan, J. A., Kaufman, Y. J., Nakajima, T., Lavenu, F., Jankowiak, I., and Smirnov, A.: AERONET - A federated instrument network and data archive for aerosol characterization, Remote Sens. Environ., 66, 1-16, 1998.

Knuteson, R. O., Revercomb, H. E., Best, F. A., Ciganovich, N. C., Dedecker, R. G., Dirkx, T. P., Ellington, S. C., Feltz, W. F., Garcia, K., Howell, H. B., Smith, W. L., Short, J. F., and Tobin, D.
C.: Atmospheric Emitted Radiance Interferometer. Part I: Instrument Design, J. Atmos. Oceanic Technol., 21, 1763-1776, 2004.

Kokkalis, P., Papayannis, A., Mamouri, R. E., Tsaknakis, G., and Amiridis, V.: The EOLE lidar system of the National Technical University of Athens, 629-632, 26th International Laser Radar Conference (26th ILRC), Porto Heli, Greece, 25-29 June 2012.

Kulmala, M., Laaksonen, A., Korhonen, P., Vesala, T., Ahonen, T., and Barrett, J.: The effect of atmospheric nitric acid vapor on cloud condensation nucleus activation, J. Geophys. Res., 98, 0148-0227, https://doi.org/10.1029/93JD02070, 1993.

Landulfo, E., Freitas, S. R., Longo, K. M., Uehara, S. T., and Sawamura, P.: A comparison study of regional atmospheric simulations with an elastic backscattering Lidar and sunphotometry in an urban area, Atmos. Chem. Phys., 9, 6767-6774, https://doi.org/10.5194/acp-9-6767-2009, 2009.

Leblanc, T. and McDermid, I. S.: Accuracy of Raman lidar water vapor calibration and its applicability to long-term measurements, Appl. Optics, 47, 5592-5602, 2008.

Leblanc, T., Walsh, T. D., McDermid, I. S., Toon, G. C., Blavier, J.-F., Haines, B., Read, W. G., Herman, B., Fetzer, E., Sander, S., Pongetti, T., Whiteman, D. N., McGee, T. G., Twigg, L., Sumnicht, G., Venable, D., Calhoun, M., Dirisu, A., Hurst, D., Jordan, A., Hall, E., Miloshevich, L., Vömel, H., Straub, C., Kampfer, N., Nedoluha, G. E., Gomez, R. M., Holub, K., Gutman, S., Braun, J., Vanhove, T., Stiller, G., and Hauchecorne, A.: Measurements of Humidity in the Atmosphere and Validation Experiments (MOHAVE)-2009: overview of campaign operations and results, Atmos. Meas. Tech., 4, 2579-2605, https://doi.org/10.5194/amt4-2579-2011, 2011.

Liljegren, L.: Microwave Radiometer Profiles Handbook, Manual, Argonne National Laboratory, Washington D.C., 2002.

Liljegren, J. C., Boukabara, S. A., Cady-Pereira, K., and Clough, S. A.: The effect of the half-width of the $22-\mathrm{GHz}$ water vapor line on retrievals of temperature and water vapor profiles with a 12channel microwave radiometer, Geosci. Rem. Sens., 43, 1102 1108, https://doi.org/10.1109/TGRS.2004.839593, 2005.

Löhnert, U. and Maier, O.: Operational profiling of temperature using ground-based microwave radiometry at Payerne: prospects and challenges, Atmos. Meas. Tech., 5, 1121-1134, https://doi.org/10.5194/amt-5-1121-2012, 2012.

Löhnert, U., Crewell, S., and Simmer, C.: An integrated approach toward retrieving physically consistent profiles of temperature, humidity and cloud liquid water, J. Appl. Meteor., 43, 12951307, 2004.

López, M. L. and Ávila, E. E.: Influence of the ambient humidity on the concentration of natural deposition-mode ice-nucleating particles, Atmos. Chem. Phys., 16, 927-932, https://doi.org/10.5194/acp-16-927-2016, 2016.

Mamouri, R. E., Papayannis, A., Tsaknakis, G., Amiridis, V., and Koukouli, M.: First water vapor measurements over Athens, Greece, obtained by a combined Raman elastic backscatter lidar system, Óptica Pura y Aplicada, 41, 109-116, 2008.

Maschwitz, G., Löhnert, U., Crewell, S., Rose, T., and Turner, D. D.: Investigation of ground-based microwave radiometer calibration techniques at $530 \mathrm{hPa}$, Atmos. Meas. Tech., 6, 2641-2658, https://doi.org/10.5194/amt-6-2641-2013, 2013.

Mattis, I., Ansmann, A., Althausen, D., Jaenisch, V., Wandinger, U., Müller, D., Arshinov, Y. F., Bobrovnikov, S. M., and Serikov, I. 
B.: Relative-humidity profiling in the troposphere with a Raman lidar, Appl. Optics, 41, 6451-6462, 2002.

Miloshevich, L. M., Vomel, H., Whiteman, D. N., and Leblanc, T.: Accuracy assessment and correction of Vaisala RS92 radiosonde water vapor measurements, J. Geophys. Res., 114, D11305, https://doi.org/10.1029/2008JD011565, 2009.

Mochida, M.: Simultaneous Measurements of Hygroscopic Property and Cloud Condensation Nucleus Activity of Aerosol Particles of Marine Biogenic Origin, Western Pacific Air-Sea Interaction Study, 71-81, https://doi.org/10.5047/w-pass.a01.008, 2014.

Nagel, D., Leiterer, U., Dier, H., Kats, A., Reichardt, J., and Behrendt, A.: High accuracy humidity measurements using the standardized frequency method with a research upper-air sounding system, Meteorol. Z., 10, 395-405, https://doi.org/10.1127/0941-2948/2001/0010-0395, 2001.

Nash, J., Oakley, T., Vömel, H., and Wei, L.: WMO intercomparison of high quality radiosonde systems, Yangjiang, China, WMO, TD, 1580, 2011.

Navas-Guzmán, F., Fernández-Gálvez, J., Granados-Muñoz, M. J., Guerrero-Rascado, J. L., Bravo-Aranda, J. A., and AladosArboledas, L.: Tropospheric water vapour and relative humidity profiles from lidar and microwave radiometry, Atmos. Meas. Tech., 7, 1201-1211, https://doi.org/10.5194/amt-7-1201-2014, 2014.

Papayannis, A., Argyrouli, A., Bougiatioti, A., Remoundaki, E., Vratolis, S., Nenes, A., Solomos, S., Komppula, M., Giannakaki, E., Kalogiros, J., Banks, R., Eleftheriadis, K., Mantas, E., Diapouli, E., Tzanis, C. G., Kazadzis, S., Binietoglou, I., Labzovskii, L., Vande Hey, J., and Zerefos, C. S.: An overview from hygroscopic aerosols to cloud droplets: The HygrA-CD campaign in the Athens basin, Sci. Total Environ., 574, 216-233, https://doi.org/10.1016/j.scitotenv.2016.09.054, 2017.

Petters, M. D. and Kreidenweis, S. M.: A single parameter representation of hygroscopic growth and cloud condensation nucleus activity, Atmos. Chem. Phys., 7, 1961-1971, https://doi.org/10.5194/acp-7-1961-2007, 2007.

Radel, G. and Shine, K. P.: Evaluation of the use of radiosonde humidity data to predict the occurrence of persistent contrails, Q. J. Roy. Meteorol. Soc., 133, 1413-1423, https://doi.org/10.1002/qj.128, 2007.

Rose, T., Crewell, S., Löhnert, U., and Simmer, C.: A network suitable microwave radiometer for operational monitoring of the cloudy atmosphere, Atmos. Res., 75, 183-200, https://doi.org/10.1016/j.atmosres.2004.12.005, 2005.

Schneider, T., O'Gorman, P. A., and Levine, X. J.: Water vapor and the dynamics of climate changes, Rev. Geophys., 48, RG3001, https://doi.org/10.1029/2009RG000302, 2010.

Schutgens, N., Tsyro, S., Gryspeerdt, E., Goto, D., Weigum, N., Schulz, M., and Stier, P.: On the spatio-temporal representativeness of observations, Atmos. Chem. Phys., 17, 9761-9780, https://doi.org/10.5194/acp-17-9761-2017, 2017.

Sherwood, S. C., Ingram, W., Tsushima, Y., Satoh, M., Roberts, M., Vidale, P. L., and O'Gorman, P.: Relative humidity changes in a warmer climate, J. Geophys. Res., 115, 1-11, https://doi.org/10.1029/2009JD012585, 2010.

Skamarock, W. C., Klemp, J. B., Dudhia, J., Gill, D. O., Barker, D., Wang, W., and Powers, J. G.: A Description of the Advanced Research WRF Version 2, technical report NCAR/TN 468+STR, https://doi.org/10.5065/D68S4MVH, available at: http://www2. mmm.ucar.edu/wrf/users/docs/arw_v2_070111.pdf (last access: 2 February 2018), 2005.

Tang, I. N., Wong, W. T., and Munkelwitz, H. R.: The relative importance of atmospheric sulphates and nitrates to visibility reduction, Atmos. Environ., 15, 2763-2471, 1981.

Theopold, F. A. and Bosenberg, J.: ifferential absorption lidar measurements of atmospheric temperature profiles: Theory and experiment, J. Atmos. Oceanic Technol., 10, 165-179, https://doi.org/10.1175/15200426(1993)010<0165:DALMOA>2.0.CO;2, 1993.

Tomkins, A. M.: Impact of temperature and humidity variability on cloud cover assessment using aircraft data, Q. J. Roy. Meteorol. Soc., 129, 2151-2170, 2003.

Turner, D. D., Feltz, W. F., and Ferrare, R. A.: Continuous Water Vapor Profiles from Operational Ground-Based Active and Passive Remote Sensors, B. Am. Meteorol. Soc., 8, 1301-1317, 2000.

Van Heerwaarden, C. C. and de Arellano, V.-G.: Relative humidity as an Indicator for Cloud Formation over Heterogeneous Land Surfaces, J. Am. Meteorol. Soc., 65, 3263-3277, https://doi.org/10.1175/2008JAS2591.1, 2008.

Veselovskii, I., Whiteman, D. N., Kolgotin, A., Andrews, E., and Korenskii, M.: Demonstration of aerosol property profiling by multi-wavelength lidar under varying relative humidity conditions, J. Atmos. Ocean. Technol., 26, 1543-1557, 2009.

Wang, L. Z.: Systematic errors in global radiosonde precipitable water data from comparisons with groundbased GPS measurements, J. Climate, 21, 2218-2238, https://doi.org/10.1175/2007JCLI1944.1, 2008.

Wang, Y., Hua, D., Mao, J., Wang, L., and Xue, Y.: A detection of atmospheric relative humidity profile by UV Raman Lidar, J. Quant. Spectr. Ra., 112, 214-219, 2011.

Ware, R., Carpenter, R., Guldner, J., Liljegren, J., Nehrkorn, T., Solheim, F., and Vandenberghe, F. A.: Multi-Channel Radiometric Profiles of Temperature, Humidity and Cloud Liquid, Radio Sci., 38, 8079-8032, 2003.

Weitkamp, C.: Lidar. Range-Resolved Optical Remote Sensing of the Atmosphere, ISSSN 0342-4111, 102 Ausg., New York: Springer Science, 2005.

Westwater, E.: Ground-based passive probing using the microwave spectrum of oxygen, Troposphere kinetic temperature structure from ground-based measurements of oxygen emission spectra in microwave region, using inverstion technique and iterative method, J. Res. Natl. Inst. Stand. Technol., 69D, 1201-1211, 1965.

Westwater, E., Crewell, S., Matzler, C., and Cimini, D.: Principles of Surface-based Microwave and Milimeter wave Radiometeric Remote Sensing of the Troposphere, Quaderni Della Societa Italiana Di Eletromagnetismo, 1, 52, 2005.

Wex, H., Stratmann, F., Hennig, T., Hartmann, S., Niedermeier, D., Nilsson, E., Ocskay, R., Rose, D., Salma, I., and Ziese, M.: Connecting hygroscopic growth at high humidities to cloud activation for different particle types, Environ. Res. Lett., 3, 035004 , 1-10, 2008.

Whiteman, D., Melfi, S., and Ferrare, R.: Raman lidar system for the measurement of water vapor and aerosols in the Earth's atmosphere, Appl. Optics, 31, 3068-3078, 1992.

Whiteman, D. N., Demoz, B., Di Girolamo, P., Comer, J., Veselovskii, I., Evans, K., Wang, Z., Cadirola, M., Rush, K., Schwemmer, G., Gentry, B., Melfi, S. H., Mielke, B., Ven- 
able D., and van Hove, T.: Raman Lidar Measurements during the International H2O Project. Part I: Instrumentation and Analysis Techniques, J. Atmos. Ocean. Tech., 23, 157-169, https://doi.org/10.1175/JTECH1838.1, 2006.

Whiteman, D. N., Rush, K., Rabenhorst, S., Welch, W., Cadirola, M., McIntire, G., Russo, F., Adam, M., Venable, D., Connell, R., Veselovski, I., Forno, R., Mielke, B., Stein, B., Leblanc, T., McDermid, S., and Vomel, H.: Airborne and Ground-Based Measurements Using a High-Performance Raman Lidar, J. Atmos. Ocean. Technol., 27, 1781-1800, https://doi.org/10.1175/2010JTECHA1391.1, 2010.

Whiteman, D. N., Venable, D. D., and Landulfo, E.: Comments on accuracy of Raman lidar water vapor calibration and its applicability to long-term measurements, Appl. Optics, 50, 2170-2176, https://doi.org/10.1364/AO.47.005592, 2011.
Wulfmeyer, V., Hardesty, R. M., Turner, D. D., Behrendt, A., Cadeddu, M. P., Di Girolamo, P., Schlussel, P., Van Baelen, J., and Zus, F.: A review of the remote sensing of lower tropospheric thermodynamic profiles and its indispensable role for the understanding and the simulation of water and energy cycles, Rev. Geophys., 53, 819-895, https://doi.org/10.1002/2014RG000476, 2015.

Zieger, P., Fierz-Schmidhauser, R., Weingartner, E., and Baltensperger, U.: Effects of relative humidity on aerosol light scattering: results from different European sites, Atmos. Chem. Phys., 13, 10609-10631, https://doi.org/10.5194/acp-13-106092013, 2013. 